\title{
@creative
}

BY-NC-SA 4.0

UMÁTICA. Revista sobre Creación y Análisis de la Imagen

\{ISSN: 2659-5354 // D.L.: MA- 1628-2018\}

\section{Las calles siguen siendo las mismas}

\section{IAN WAELDER}

ianwaelder@gmail.com

Mi relación con Alemania es un tanto extraña. Mi apellido es alemán, pero no sé decir más de un par de frases. Mañana a las cinco tengo mi primera clase. Mientras escribo estas líneas me encuentro recién llegado desde Barcelona a Frankfurt am Main, ciudad que será mi casa durante los próximos años. La mayoría de la gente pasa por la estación central de esta ciudad antes de dirigirse a Kassel. Tras varios meses tratando de buscar dónde alojarme indefinidamente, tan sólo he podido encontrar una habitación durante un mes en el barrio de Sachsenhausen; un nombre que aquí es sinónimo de zona agradable con buenos lugares en los que ir a comer o simplemente pasear, por lo que os podréis imaginar que la habitación no me ha salido barata. Lo que me inquieta es que comparte nombre con un conocido campo de concentración que hubo en Oranienburg. Mi abuelo paterno era pianista y nació en Stuttgart. Fue llevado por los nazis al campo de concentración de Welzheim tras su detención en la noche de los Cristales Rotos del 9 de noviembre de 1938 y escapó en marzo de 1939, pasando por Génova para huir a Chile en barco. Hace muy poco supe que mis bisabuelos fueron llevados al campo de concentración de Riga, en Latvia, y a partir de entonces se perdió la pista.

Llegué por primera vez a Kassel en 2014, sin documenta de por medio, a través de un intercambio-residencia en Tokonoma Apartment, un colectivo que lleva un espacio en el centro de la ciudad y donde se organizan exposiciones, charlas y conciertos. Fui de la mano de la mejor compañía; amigos pero también artistas y comisarios como Irene de Andrés, Cristina Garrido, Ángel Calvo Ulloa, Inez Piso y Ana

CÓMO CITAR ESTE TRABAJO / HOW TO CITE THIS PAPER

Waelder, lan (2018). La calles siguen siendo las mismas. Umática. Revista sobre Creación y Análisis de la Imagen , 1: $173-178$.

http://dx.doi.org/10.24310/Umatica.2018.voi1.5412

Umática. 2018; 1: 173-178 
Esteve Reig. Ana fue quien nos hizo de guía ya que conocía muy bien la ciudad tras haber estudiado allí la carrera en la Kunsthochschule, en la clase del excelente artista Björn Melhus. Fue un viaje bastante intenso ya que creo recordar que no llegamos a estar más de una semana y media y teníamos que preparar un proyecto conjunto de exposición mientras íbamos conociendo los rincones y secretos de la vida en Kassel -vida en Kassel sin documenta, importante remarcarlo- de forma paralela. Se nos repetía mucho aquello de que era una pena no haber coincidido con el acontecimiento, pero pudimos ver que pese a no haber documenta se podía encontrar una programación interesante y que había una escena. De todas formas me llevé la impresión de que hay parte de la comunidad que siente cierto rechazo al desembarco de la documenta. Será que no debe de ser agradable que a uno lo confundan con un guía de la documenta constantemente, por mucho que tan sólo sean cien días cada cinco años. En mi visita a la reciente edición del acontecimiento artístico pude observar varias cartelas en múltiples establecimientos advirtiendo de que no nos molestemos en preguntarles sobre la documenta porque no sabían nada. Aportaban un aire cómico al ambiente.

Antes de mi primera visita a Kassel hace tres años, mis referencias sobre la documenta eran muy básicas. La idea general que comenzó como un resurgimiento cultural en la ciudad tras los bombardeos sufridos en la Segunda Guerra Mundial, que dejaron el centro prácticamente inexistente, con la intención de volver a conectar Alemania con el mundo exterior.
"Kassel no invita a la lógica" de Enrique Vila-Matas fue un libro que cuando se publicó estuvo en boca de mucha gente, sobretodo del mundo del arte por supuesto. Salían varios artículos halagadores sobre el libro en relación a la Documentaiz pero al contrario que con otras obras suyas, éste no fue un libro que yo disfrutase especialmente y lo dejé a medias. De todas formas, en saber de la residencia, le di otra oportunidad a modo de sprint para tener una referencia un poco más reciente durante los paseos por la ciudad sin documenta. Desde la llegada a la estación de Kassel, obviamente todo eran conexiones con las anécdotas que comentaba VilaMatas en su libro y mi obsesión principal era ir a buscar el famoso restaurante chino, cosa que nunca hicimos finalmente.

Con la llegada de la documenta de esta edición, pensé: Joder, ¿cinco años han pasado ya desde 2012? Por aquel entonces yo comenzaba a darme cuenta de lo que se hacía en el arte contemporáneo y lo que era el "mundo del arte". El mismo día que supe sobre la documenta, fue el mismo día que cerraba. Me sentó fatal tener que esperar cinco años para poder descubrir aquella maravilla de acontecimiento de la que tanto se me hablaba. La mayoría de cosas las fui aprendiendo gracias a mi padre, que es escultor, y a mi hermano Pau, que es comisario. Él fue clave para poder estar al tanto de lo que se iba haciendo en arte contemporáneo y tener a alguien con quien debatir sobre el panorama actual en las mesas familiares o a quien acudir cuando tenía alguna duda.

Antes de inaugurarse la edición de este año de la documenta, mi hermano me propuso hacer

Umática. 2018; 1: 173-178 


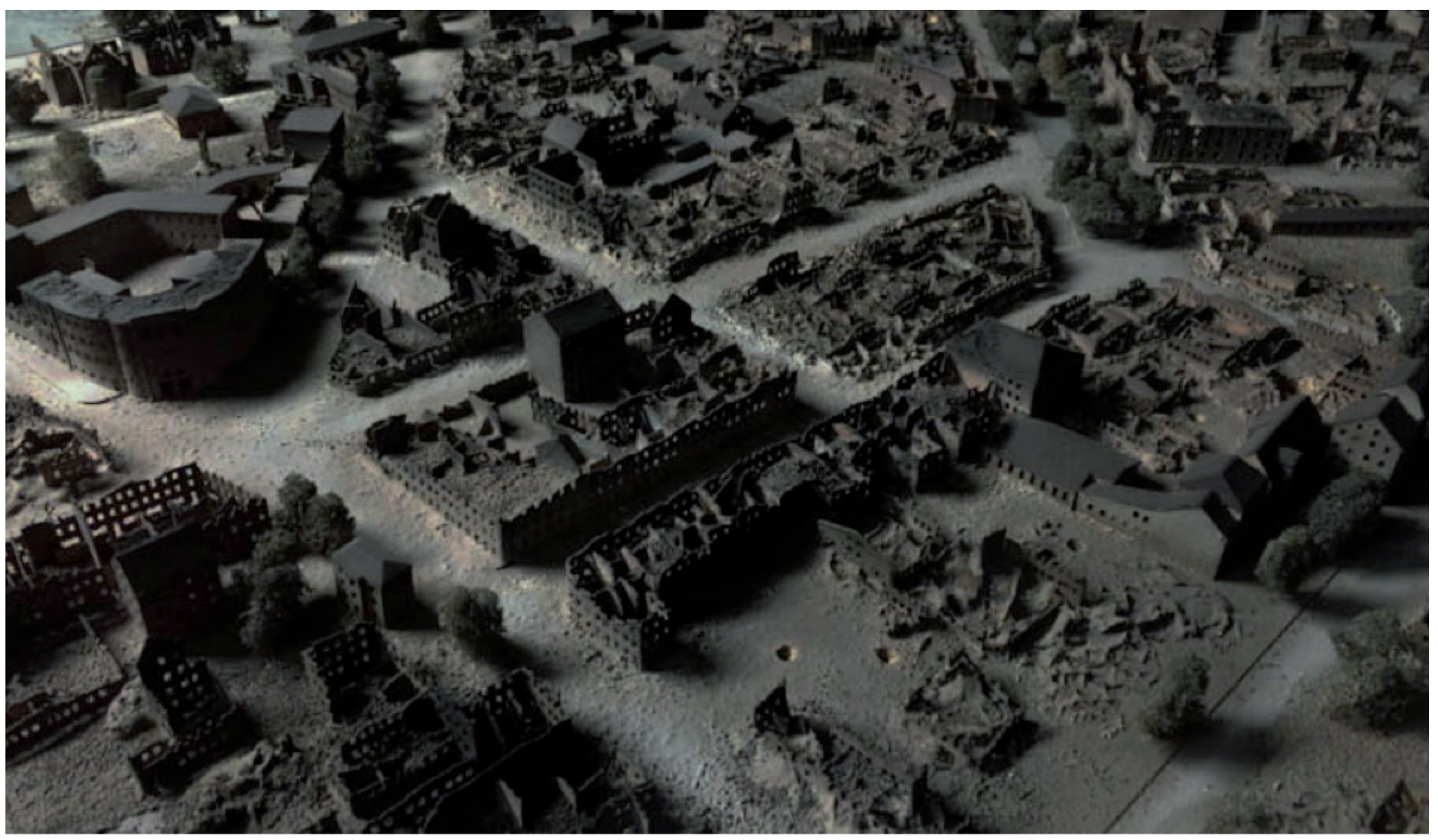

el viaje juntos. Caí en la cuenta de que nunca habíamos hecho un viaje juntos que no fuera una quedada familiar y menos para ir a ver arte. La semana antes del viaje, me encontraba terminando el libro Dietario voluble de Vila-Matas, en los que describe su día a día y diferentes anotaciones. Uno no puede evitar fantasear con cruzárselo cuando menciona las calles por las que transita. De repente, en Rambla de Catalunya, mientras paseaba con mi pareja, se me cruzó de frente acompañado de la escritora Cristina Fernández Cubas. Acababan de entrar en una bodega y yo, por muy maleducado que pudiera parecer, no pude evitar no seguirles. Me acerqué a su mesa y entre tartamudeos le pregunté si no le importaría dedicarme su último libro, Mac y su contratiempo, que casualmente llevaba en la mochila. Fue muy abierto y simpático. Entre otras cosas pude hablar con él sobre la documenta. Me dijo que recién salía a la venta una "edición de lujo" de Kassel no invita a la lógica y que en su opinión estaba demasiado caro. No estaba cómodo con la idea. Al salir de aquel lugar pude ver que le había dedicado el libro a un tal Biel, pero no pasa nada. Júlia, que me acompañaba, se reía.

Una semana después, el 10 de julio, mi hermano y yo llegamos a Kassel a eso de las seis de la tarde tras el viaje de casi un par de horas en tren desde Frankfurt. El cielo no se veía muy amable y nos quedaba camino para llegar al hotel, así que decidimos comprar unos paraguas. Me fijé en la parada de libros de la tienda y allí estaba: Kassel: Eine Fiktion. El libro caro de VilaMatas. Y la traducción del título sin rodeos. Qué directo es este idioma.

Tras salir unos pasos de la estación, sentí que el tiempo entre mi última visita en $2014 \mathrm{Y}$ la de ese momento se habían acortado a unos días de diferencia. Y comenzó a llover muchísimo. Mientras caminábamos por la ciudad bajo nuestros paraguas, comencé a entender algunos espacios vacíos que vi en 2014 y que ahora iban acompañados de señaléticas con la identidad -algo confusa- de la Documental4. Nos metimos en un tram, casi de forma aleatoria, para llegar al hotel que habíamos reservado a las afueras. Dejaba de llover, así que una vez llegados a la habitación, lanzamos nuestras cosas y fuimos
Fig.o1.

Hiwa K. View from Above (2017)

Digital video, color, sound. 11:23 min. Stadtmuseum Kassel, Kassel 
directamente a la zona del Fridericianum a planear nuestros próximos dos días y medio. Sí, muy poco tiempo.

Lo primero que nos encontramos al llegar fueron los puestos de entradas y merchandising. Era como la entrada a Port Aventura. Tazas, bolígrafos, gomas de borrar, pañuelos... todo lo que te puedas imaginar, estampado con el logo de documenta. Te ofrecen, o empujan, a tener un souvenir que sirva como recuerdo antes de haber vivido la experiencia. Que la gente sepa que has estado allí a través de tu llavero o tote bag. Y como no, nosotros picamos. El chubasquero era muy bonito.

Por el camino uno se topaba con varias Stolpersteines, proyecto que comenzó Gunter Demnig en los noventa. Las Stolpersteines son unos cubos de cemento que dejan a la vista unas placas cuadradas de latón de $10 \mathrm{~cm}$ por lado. Se colocan en la calzada frente al último lugar de residencia voluntaria de las víctimas del nazismo y llevan siempre el nombre de la víctima y las fechas de nacimiento, deportación y muerte. Gracias a este proyecto pude saber sobre mis bisabuelos. Las placas están colocadas por toda Alemania y van extendiéndose por el resto de Europa. Verlas me hacía recordar a mi familia, el pasado de Kassel, del país, todo lo que vino después. Cómo estamos ahora. Me hizo pensar también en cómo la documenta ha superado con creces ese objetivo de comunicarse con el mundo exterior tras el desastre de la Segunda Guerra Mundial, pero a la vez me hace sospechar que lo que vemos hoy en documenta transcienda más allá del mundo del arte. En el caso de este año la presencia de la crisis de los refugiados y la económica está muy presente pero, ¿en qué queda todo realmente? Uno ve cómo cierto número de artistas hablan sobre estos sucesos en su obra mientras el valor de su trabajo en el mercado sube tras su presencia en la exposición. Cosa que es difícil de separar y nos lleva a otro debate. Me remueve el estómago llevar el foco a temas tan importantes mientras el mundo del arte continúa con unos códigos que se contradicen continuamente. Si uno lee la lista de patrocinadores de documenta se cuestionará por qué documenta sí y mojarse a nivel político no. Hay demasiadas formalidades y acuerdos, y muchas vidas que dependen de esas normas de actuación. Leyendo y releyendo el Readers Book no podía evitar cuestionarme si no era más que paja entre académicos lo que veían mis ojos, por muchas cosas interesantes que pudieran mencionarse. ¿Qué sentido tiene documenta hoy más allá de para nosotros mismos, como "consumidores" de arte?

Consciente de la complejidad del tema que acabo de mencionar, mejor volvamos al viaje. Antes de comenzar la ruta por la documental4, sentía haberlo visto todo en Instagram desde la inauguración, y en la cantidad de webs con artículos del estilo "Las 10 obras que no debes perderte en documenta14", "Los 15 artistas más importantes de documenta14", etc. Leyendo otro tipo de artículos más serios, uno ya veía que la tónica general hacia la edición de este año era bastante negativa. La parte de documenta celebrada en Atenas parecía haber sido un fracaso o un sin sentido según la crítica especializada, y la parte de Kassel tampoco era muy bien recibida. Intenté borrar de mi memoria todo cuanto pude sobre lo que había leído para tratar de ver la exposición de este año con la menor contaminación posible. 
La situación sí que fue un tanto decepcionante debido a algo imposible de controlar, y fue la afluencia de público, que a la vez es una buena señal. Aún así la experiencia fue como estar en una inauguración constante. La cantidad de gente que inundaba las salas hacía difícil poder ver con claridad las obras, que las había que eran excelentes. La imagen que tenía en la cabeza sobre documenta fue siempre una especie de parque de atracciones -esta vez en el buen sentido, como vista por un niño o una niña- donde uno se encuentra propuestas que son un golpe tras otro. Pura emoción y sorpresa. Pero claro, olvidé que en todo parque hay colas. $Y$ no podía evitar sentirme sedado ante la cantidad de propuestas que había en cada espacio. No me atrevería a decir que esta edición fuera un fracaso, porque considero que la documenta consta de un formato donde el tiempo se estira. Uno no puede visitar la documenta en dos o tres días, sobretodo en una edición donde una gran cantidad de propuestas parten de una intención historiográfica y con mucho texto complementario. Hay una inmensa cantidad de información que digerir. Es una exposición que se funde con la ciudad, hay que convivir con la documenta y por eso me parece un tanto absurdo, o hasta poco fiable, leer críticas por parte de gente que ha ido tres días, probablemente tragándose cada exposición en treinta minutos y corriendo a por la siguiente. Al menos esa era la única forma de ver la mayoría de cosas que nos apetecía ver a nosotros en tan poco tiempo.

De todas formas, ya en nuestro último día tras un largo recorrido -que incluyó haber ido a comer al Dschingis Khan de Vila-Matas- y a punto de terminar la ruta antes de marchar en coche a Münster a la mañana siguiente, pudimos ver dos obras que conectaban a la perfección y me dejaron un muy buen sabor de boca. Aprovechamos para pasar por el CineStar para ver la última pieza de uno de mis artistas fetiche, Douglas Gordon: "I Had Nowhere to Go: A Portrait of a Displaced Person" (2016). No podré negar que era muy de agradecer el poder disfrutar de una pieza de vídeo en una sala de cine -esas butacas, qué gusto- sobretodo cuando uno lleva horas y horas caminando sin parar. La forma en que relata la autobiografía de Jonas Mekas donde él mismo narra sus vivencias durante la Segunda Guerra Mundial, en forma de retrato ausente, me pareció excepcional. Sin duda era el "boom" -literalmente hablando- que necesitábamos. Este era el tipo de discursos que esperaba de la documenta y que me conectaban de una forma descarada a los crudos relatos narrados por Mekas.

Salimos de la sala del CineStar algo aturdidos y destellados por la luz tras haber pasado unos noventa minutos en plena oscuridad. Nos sentimos cargados de energía y procedimos la ruta hacia el Stadtmuseum. Y aquí fue donde me encontré con la perla de la documenta, que llegaba con un discreto vídeo de once minutos de duración por parte del artista iraquí Hiwa K, titulado "View from above" (2017). Era una pieza mucho más silenciosa y sutil que su instalación escultórica frente al Fridericianum y que rondaba por todos los Instagrams en aquellos días.

"View from above" nos mostraba una grabación en movimiento a vista áerea de una maqueta de la ciudad de Kassel tras los bombardeos, mientras que en una dulce y suave voz en off relataba la historia de un refugiado. Hablaba del 
intento de éste en pasar a la "zona segura", teniendo que demostrar al guardia que provenía de la "zona no segura" para poder acceder y comenzar una vida nueva. Se muestra un choque de percepción ya que el guardia que entrevista al aspirante -y a tantos otros cientos de miles- para pasar a la "zona segura", espera respuestas basándose en la vista aérea de su mapa, cosa que los refugiados difícilmente pueden conseguir ya que se basan en su punto de vista real de a pie. Y uno ve cómo esa misma falta de percepción es la que tienen la mayoría de personas que nos gobiernan en este mundo.

Tras ver el vídeo por tercera vez, continué el recorrido hacia las siguientes salas. Tratándose

AUTOR:

lan Waelder es co-fundador de Printer Fault Press junto a Óscar Florit. Estadounidense nacido en Madrid en 1993. Vive y trabaja en Frankfurt am Main, Alemania. Su práctica artística explora la materialidad urbana desde la memoria con aquellos medios que tiene a su alcance, desde fotografía a sonido, pasando por texto, pintura o escultura. Es también

la práctica del coleccionista aplicada a lo experiencial: una investigación de los trazos y las marcas que los sujetos dejan en los objetos y el entorno material.

Correspondencia: ianwaelder@gmail.com del Stadtmuseum por supuesto te encontrabas con la historia de la ciudad. Vitrinas con todo tipo de objetos del ejército nazi, un cuadro de un edificio de Kassel con banderas de la esvástica y unos pasos más adelante, una sala con la misma maqueta de la ciudad bombardeada que aparecía en el vídeo de Hiwa K. Sin palabras.

Al salir del museo, pude reconocer gracias a las calles y plazas los edificios y partes nuevas construidas que poco antes vi en ruinas en la pieza de Hiwa K. Pude ver también cómo la gente seguía con las costumbres alemanas que vienen de tan atrás y que son tan cliché como los frankfurts, los bretzels o la cerveza. Otras costumbres fueron borradas. En la parada del tram, de vuelta al hotel, algo me hizo dar un sobresalto. Me di cuenta de que estaba situado prácticamente en el mismo punto de vista que el pintor que hizo el cuadro que vi en el Stadtmuseum, donde se veía la escena de un edificio institucional con banderas. Me imaginé junto a ese pintor, en ese contexto, pintando cuidadosamente ese escenario que hoy en día asociamos más a las películas. Recordé a mi abuelo huyendo hacia Chile, a mis bisabuelos asesinados en Latvia, y recuerdo ahora un fragmento de un texto del escritor chileno Roberto Bolaño de primeros del dos mil, sobre el cambio en la ciudad de Santiago después de la dictadura: los nuevos edificios, las nuevas avenidas, no significan nada. Las calles de Santiago siguen siendo las mismas que hace noventa y ocho años. Santiago está igual que cuando caminaban por sus calles Teófilo Cid o Carlos de Rokha. Todavía vivimos en la Revolución Francesa. Los ciclos son mucho más extensos y más densos y veinticinco años no son nada.

Umática. 2018; 1: 173-178 